\title{
Perancangan Knowledge Management System pada Bagian Diklat PT Dirgantara Indonesia
}

\author{
Joeliaty \\ Ajeng Pritha Aryani \\ Program Studi Manajemen Dan Bisnis \\ Fakultas Ekonomi Dan Bisnis \\ Universitas Padjadjaran
}

\begin{abstract}
The problem that emerged on every organization now days especially company is how to increase sustainable knowledge from their human resources that suitable with the challenges faced. However, a lot of organizations such as PT Dirgantara Indonesia is not yet or have not discovered hidden knowledge within their employees. Therefore, the objective of this research is to find a constructive plan, implementation and evaluation of Knowledge Management System (KMS) that should be applied to PT Dirgantara Indonesia. Research method used on this paper is descriptive qualitative methodology, 10-step knowledge management roadmap, and differentiation quantitative test. The results from this research are implementations on business startegy of PT Dirgantara Indonesia on their Training and Education Department, with personal approach. Knowledge that needs to be followed is career analysis method, English language ability, SAP creation and system analysis. Those implementations are running through online forum such as intranet portal and offline forum such as scheduled formal forum.
\end{abstract}

Keywords : knowledge management strategy, knowledge management system, 10 steps roadmap, SECI model, MOODLE

\section{I.Pendahuluan}

Perubahan dunia ini mengarah ke fenomena bahwa sumber ekonomi bukan lagi dalam bentuk money capital atau sumber daya alam, tapi ke arah knowledge capital. Persaingan ini oleh Peter F. Drucker disebut sebagai "knowledge to knowledge competition". Artinya, semakin kuat pengetahuan dari SDM suatu organisasi, semakin kuat daya saingnya. Maka, masalah yang dihadapi setiap organisasi, khususnya perusahaan, pada saat ini adalah bagaimana agar perusahaan mampu meningkatkan pengetahuan secara berkelanjutan dari SDM-nya yang sesuai dengan tuntutan tantangan yang dihadapi.

Namun, banyak organisasi belum atau tidak mengetahui potensi pengetahuan tersembunyi yang dimiliki oleh karyawannya. Setiap orang mengetahui bahwa organisasinya mengetahui sesuatu, tetapi seringkali tidak tahu bagaimana mendapatkan informasi tersebut atau mendapatkan nama ahli terkait informasi tersebut (Burk 1999). Hal ini didukung oleh Riset Delphi Group yang menunjukkan bahwa pengetahuan dalam organisasi tersimpan dalam struktur : 42\% dipikirkan (otak) karyawan, 26\% dokumen kertas, 20\% dokumen elektronik, $12 \%$ knowledge base elektronik. Fakta umum ini memang terjadi dimana-mana, bahwa aset pengetahuan sebagian besar tersimpan dalam pikiran kita yang disebut tacit knowledge. Oleh karena itu, knowledge management ada untuk menjawab persoalan ini yang proses mengubah 
tacit knowledge menjadi knowledge yang mudah dikomunikasikan dan didokumentasikan (explicit knowledge).

Kesadaran untuk menerapkan pendekatan knowledge management ke dalam strategi bisnis diperlukan karena terbukti perusahaan yang menjadikan pengetahuan sebagai sumber daya utamanya senantiasa mampu mendorong perusahaan lebih inovatif yang bermuara pada kepemilikan daya saing perusahaan. Posisi pengetahuan yang sedemikian penting dalam konteks daya saing perusahaan saat ini membuat Komite Malcolm Baldrige memasukkan kriteria knowledge management ke dalam salah satu dari tujuh kriteria penilaiannya.

PT Dirgantara Indonesia atau Indonesian Aeorospace (IAe) adalah industri pesawat terbang yang pertama dan satu-satunya di Indonesia dan di wilayah Asia Tenggara. Perusahaan ini dimiliki oleh Pemerintah Indonesia. PT DI didirikan pada 26 April 1976 dengan nama PT Industri Pesawat Terbang Nurtanio dan BJ Habibie sebagai Presiden Direktur. Industri Pesawat Terbang Nurtanio kemudian berganti nama menjadi Industri Pesawat Terbang Nusantara (IPTN) pada 11 Oktober 1985. Setelah direstrukturisasi, IPTN kemudian berubah nama menjadi Dirgantara Indonesia pada 24 Agustus 2000. PT DI didukung oleh 3.720 tenaga kerja yang semula berjumlah 9.670 orang.

Dalam rangka menyediakan sumber daya teknisi pendukung produksi part pesawat terbang pada tahun 1978 dibentuklah PUSDIKLAT di bawah Direktorat Umum. Dalam perkembangannya PUSDIKLAT berubah menjadi Diklat yang merupakan pusat penyelenggaraan training baik teknis maupun nonteknis di bawah Departemen Pelatihan dan Pengembangan SDM. Diklat kini hanya memiliki 12 orang karyawan setelah adanya lay off massal.

Bagian Diklat yang merupakan pusat penyelenggaraan training memiliki peran penting dalam proses operasional di PT Dirgantara Indonesia. Dengan jumlah karyawan yang sedikit, Diklat harus terus mampu menjadi 'penyedia kompetensi' bagi karyawan PT DI secara terus menerus dan berkelanjutan. Dalam pelaksanaannya, masing-masing individu menjadi spesialis dan tidak adanya pendistribusian pengetahuan antarkaryawan.

Dengan banyaknya pengetahuan yang terus mengalir, maka perlu ditangkap, diklasifikasi, disimpan, disebarkan, dan diaplikasikan sehingga menjadi nilai pengetahuan yang bermanfaat untuk meningkatkan kualitas pekerjaan karyawan dan keberlangsungan training di Diklat.

Berdasarkan latar belakang penelitian yang telah dijabarkan diatas, maka dirumuskan masalah yang akan dianalisis sebagai berikut : Bagaimana perbandingan metodologi knowledge management secara teori dan praktek? Bagaimana perancangan knowledge management system yang sebaiknya diterapkan di bagian Diklat PT Dirgantara Indonesia yang mencakup pemilihan infrastruktur teknologi, penerapan model SECI, rancangan implementasi KMS, portal intranet, pengelolaan implementasi (perubahan, budaya, dan reward), dan instrumen evaluasi KMS? Tujuan dan manfaat penelitian ini adalah untuk mendapatkan perbandingan metodologi knowledge management secara teori dan praktek dan untuk mendapatkan rancangan knowledge management system yang sebaiknya diterapkan di bagian Diklat PT Dirgantara Indonesia yang mencakup pemilihan infrastruktur teknologi, penerapan model SECI, rancangan implementasi KMS, portal intranet, pengelolaan implementasi (perubahan, budaya, dan reward), dan instrumen evaluasi KMS. 


\section{Kajian Pustaka}

Tiwana (2000) mendefinisikan knowledge management sebagai pengelolaan knowledge perusahaan dalam menciptakan nilai bisnis (business value) dan menghasilkan keunggulan kompetitif yang berkesinambungan (sustainable competitive advantage) dengan mengoptimalkan proses penciptaan, pengomunikasian, dan pengaplikasian semua knowledge yang dibutuhkan dalam rangka pencapaian tujuan bisnis. Davidson dan Voss (2002) mendefinisikan knowledge management sebagai sistem yang memungkinkan perusahaan menyerap pengetahuan, pengalaman, dan kreativitas para stafnya untuk perbaikan kinerja perusahaan. Sementara menurut Karl-Erick Sveiby (1998) knowledge management adalah seni penciptaan nilai dari intangible asset.

Menurut Paul L. Tobing (2007), knowledge management system adalah mekanisme dan proses yang terpadu dalam penyimpanan, pemeliharaan, pengorganisasian informasi bisnis dan pekerjaan yang berhubungan dengan penciptaan berbagai informasi menjadi aset intelektual organisasi yang permanen.

Michel Polanyi (1966) membedakan pengetahuan dalam dua bentuk yaitu tacit dan explicit knowledge. Tacit knowledge adalah pengetahuan yang masih berada dalam otak atau pikiran manusia/individu yang tersimpan dalam pengalaman individu dan faktor-faktor tak berwujud, seperti kepercayaan pribadi, perspektif, dan sistem nilai. Tacit knowledge sulit untuk diartikulasikan dengan bahasa formal. Isinya mencakup pemahaman pribadi, intuisi, dan firasat. Sebelum dikomunikasikan, tacit knowledge harus diubah dalam bentuk kata-kata, model, atau angka-angka yang dapat dipahami. Explicit knowledge atau terkadang disebut pengetahuan formal adalah pengetahuan yang dapat diartikulasikan dan telah dikodifikasikan sehingga bisa disampaikan dalam bahasa, juga termasuk nomor dan kata, tanda matematika, spesifikasi, manual, dal lainnya. Pengetahuan eksplisit juga siap disebar pada yang lainnya. Selain itu pengetahuan eksplisit bisa dengan mudah diproses oleh komputer, alat elektronik, atau basis data penyimpanan.

Nonaka dan Takeuchi (The Knowledge Creating Company, 1995 : 63-69) lebih lanjut mendiskusikan empat gaya konversi atau ciptaan pengetahuan yang diperoleh dari kedua macam pengetahuan. Keempat gaya konversi ini disebut model SECI (S:Sosialization, $\boldsymbol{E}$ :Externalization, $\boldsymbol{C}$ : Combination, ,dan I:Internalization). Model pertama diberi nama oleh Nonaka dan Takeuchi (1995) dengan istilah sosialisasi. Sosialisasi meliputi kegiatan berbagi pengetahuan tacit antar individu. Model kedua adalah eksternalisasi. Eksternalisasi membutuhkan penyajian pengetahuan tacit ke dalam bentuk yang lebih umum sehingga dapat dipahami oleh orang lain. Model yang ketiga, kombinasi meliputi konversi pengetahuan eksplisit ke dalam bentuk himpunan pengetahuan eksplisit yang lebih kompleks. Model terakhir, internalisasi pengetahuan baru merupakan konversi dari pengetahuan eksplisit ke dalam pengetahuan tacit organisasi.

Hansen dan kawan-kawan (1999) mengemukakan bahwa ada dua jenis strategi knowledge management, yakni strategi kodifikasi dan personalisasi. Strategi kodifikasi adalah salah satu strategi KM yang menitikberatkan perhatian sistem knowledge management organisasi terhadap pengelolaan explicit knowledge, termasuk di dalamnya penggunaan database pengetahuan yang tersimpan dalam storage komputer/server. Strategi personalisasi adalah strategi KM yang meniktikberatkan sistem knowledge management organisasi terhadap 
konektivitas antar individu. Strategi ini biasanya dipakai pada organisasi yang memerlukan penggunaan tacit knowledge yang tinggi di dalam suatu organisasi.

\section{III.Metode Penelitian}

Penelitian ini dilakukan di PT Dirgantara Indonesia bagian Diklat, yang terdiri dari 12 karyawan, sebagai populasi. Untuk melakukan penelitian ini, penulis menggunakan metode penelitian deskriptif kualitatif untuk melakukan prosedur penyusunan rancangan knowledge management system, yang mengacu pada metodologi 10-step Knowledge Management Roadmap sebagai berikut :

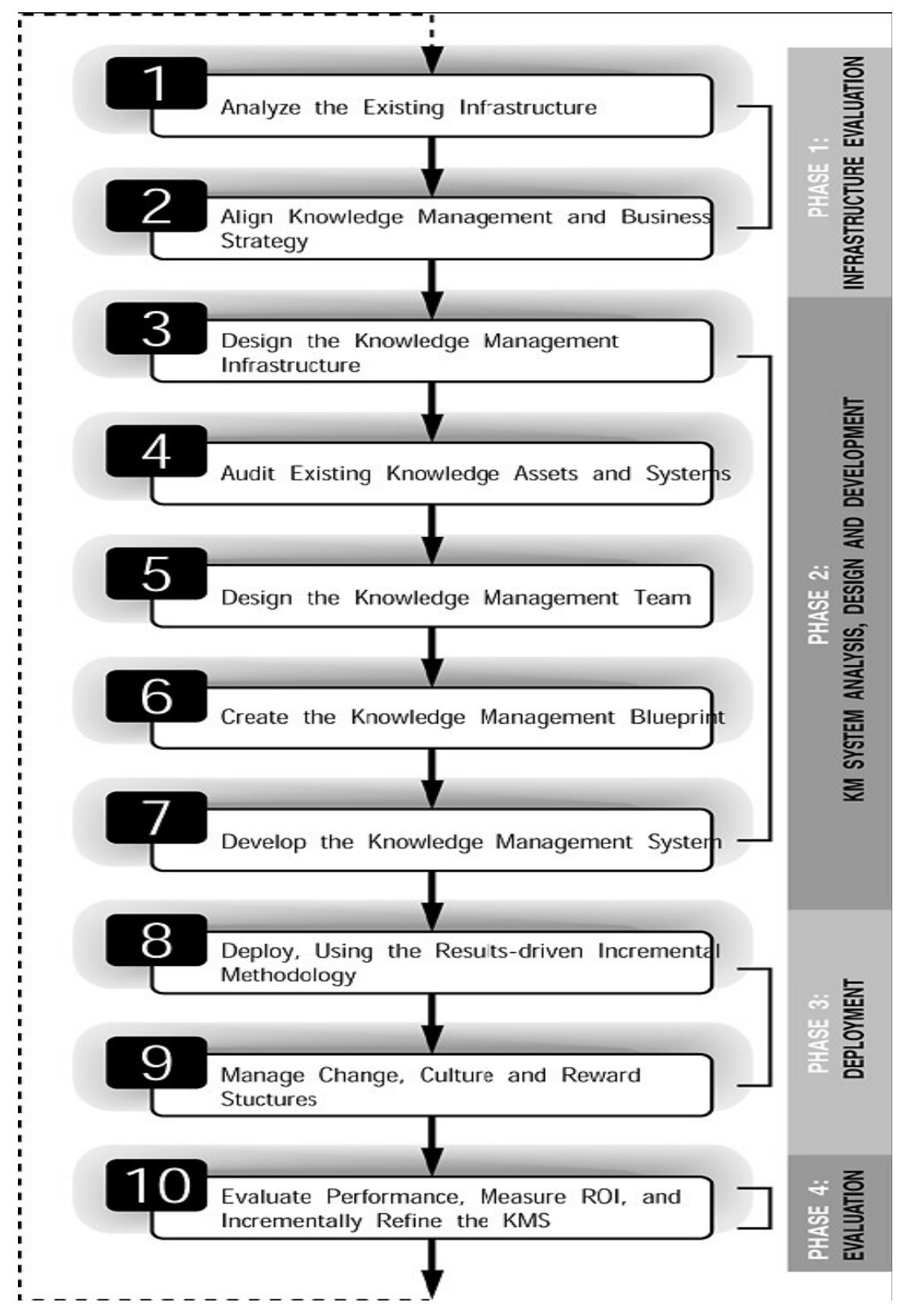

Sumber : Amrit Tiwana (2000: 101) 
Sedangkan untuk mengetahui strategi penerapan manajemen pengetahuan yang dilakukan PT Dirgantara, digunakan metode uji beda antara strategi personalisasi dan strategi kodifikasi.

\section{IV.Hasil dan Pembahasan}

Berikut adalah langkah-langkah metodologi 10 step roadmap yang dilaksanakan PT Dirgantara Indonesia Bagian Diklat.

Langkah 1 : Analisis Infrastruktur

Keadaan infrastruktur Diklat :

- Telah memiliki jaringan LAN dan dimanfaatkan untuk keperluan internet (128 Kbps) dan intranet (100 Mbps)

- Topologi jaringan LAN : star dan peer to peer

- Hardware yang dimiliki : 5 komputer di ruangan kelas, 12 komputer utk masingmasing karyawan, 2 laptop, 7 printer, dan 5 unit telepon

- Software yang dimiliki : OS, Ms. Office, Visual Basic, PHP, MySql, Camtasia, CATIA, Adobe Acrobat, Browser

- Keperluan intranet menggunakan Ms. Outlook dengan email add masing-masing yang telah diberikan perusahaan

- Keperluan internet menggunakan 2 user id yang digunakan secara bergantian

- Secara keseluruhan para karyawan sudah merasa cukup dengan infrastruktur yang ada tetapi masih merasa kurang pada memory komputer terutama untuk keperluan explorasi database dan penggunaan CATIA Advance.

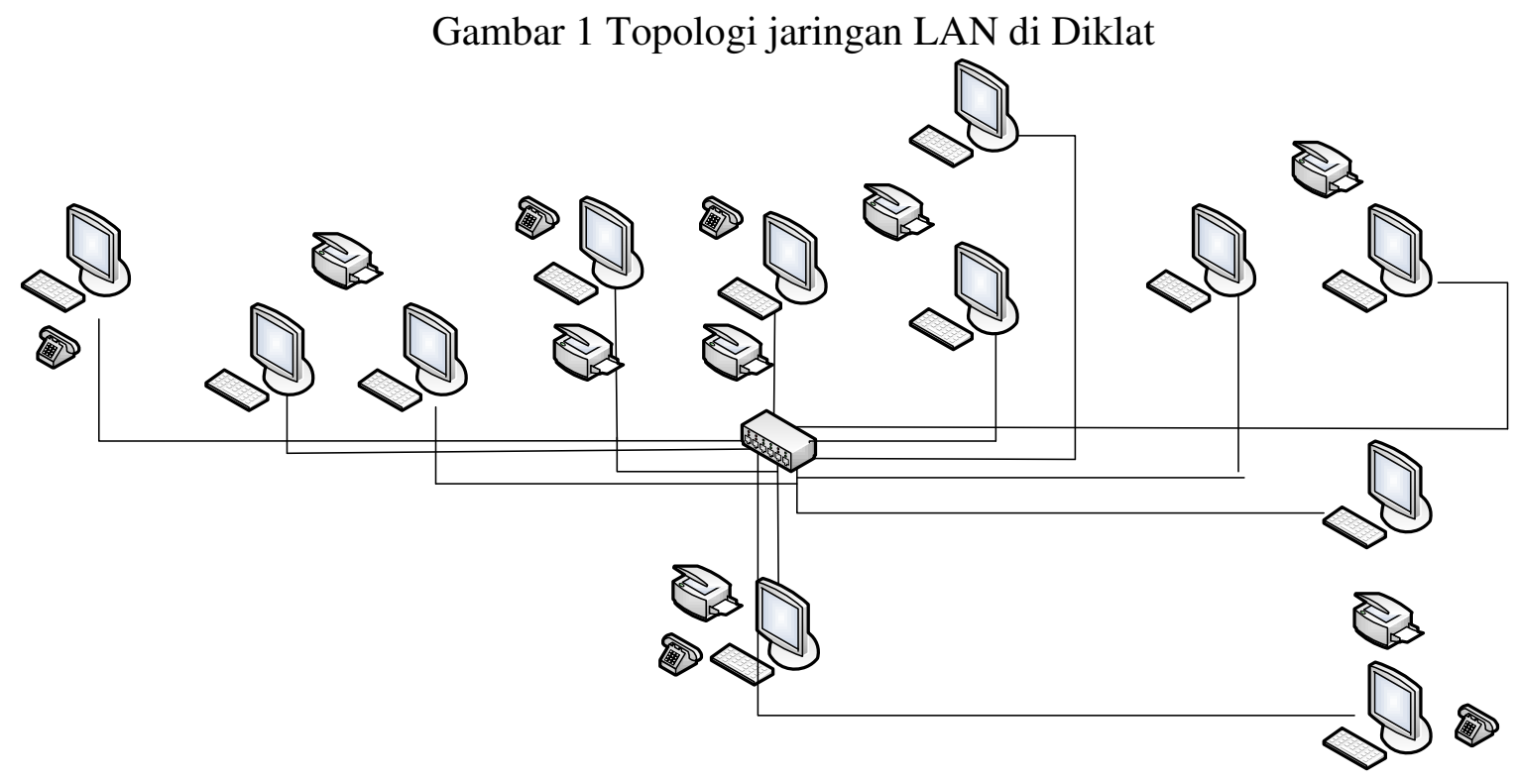

Sumber : Data primer yang diolah, 2010 
Langkah 2 Mengintegrasikan Knowledge Management Dengan Strategi Bisnis

Tabel 2 Analisis SWOT

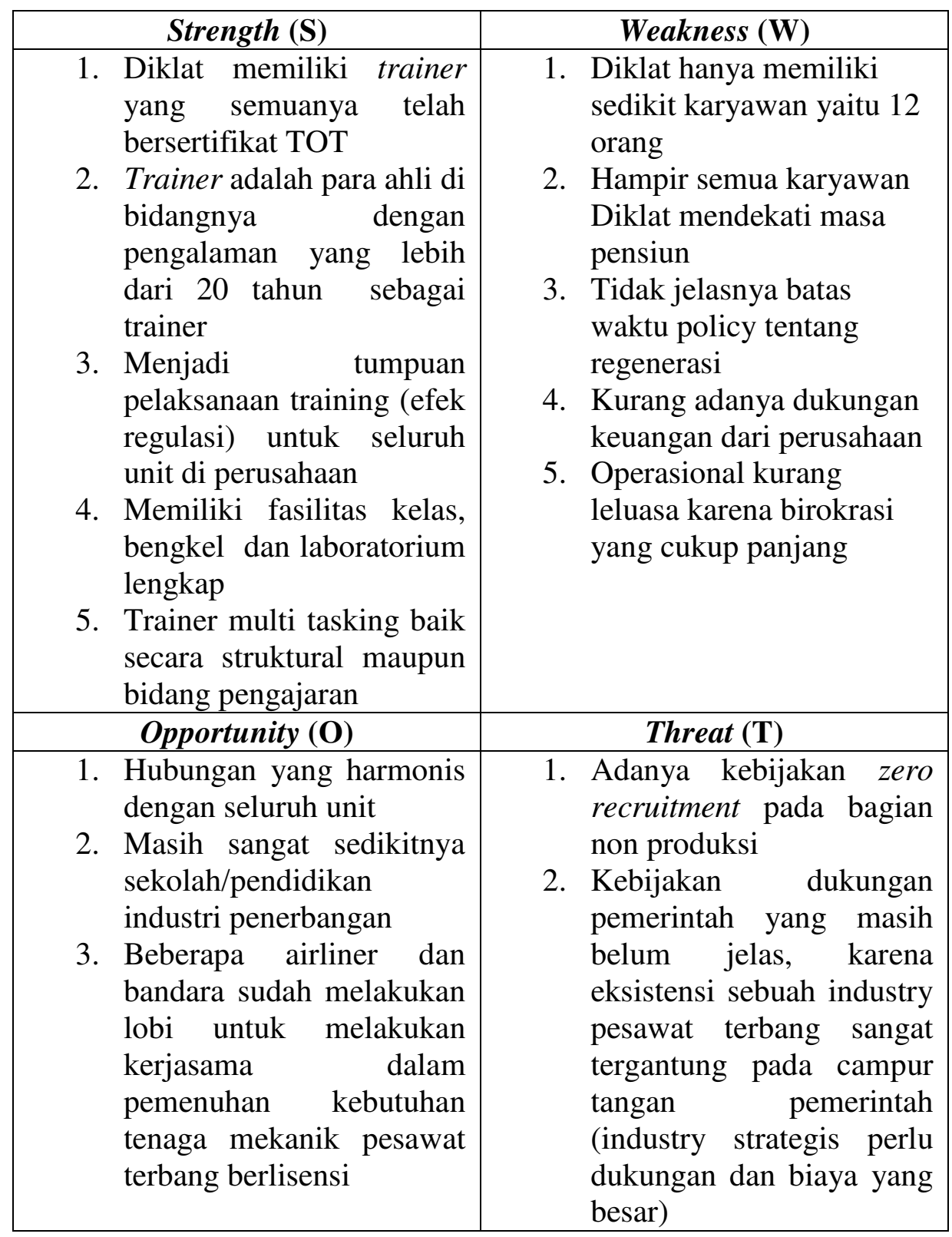

Sumber : Data primer yang diolah, 2010

Dengan memperhatikan kekuatan (S), kelemahan (W), peluang $(\mathrm{O})$, dan ancaman $(\mathrm{T})$, maka strategi yang dapat dilakukan Diklat PT DI adalah :

1. Analisis kekuatan $(\mathrm{S})$ dan peluang $(\mathrm{O})$ :

- mengembangkan Diklat sebagai training center pencetak tenaga mekanik pesawat terbang yang berlicense 
2. Analisis kekuatan (S) dan ancaman (T) :

- Meningkatkan pembelajaran para trainer dengan penyediaan sumber-sumber atau tools pembelajaran

- Mengadakan forum-forum untuk mengevaluasi metode pelatihan yang ada agar kualitasnya bisa meningkat dan tetap hemat biaya

3. Analisis kelemahan (W) dan peluang $(\mathrm{O})$ :

- Mengadakan kerja sama dengan pihak eksternal untuk menyelenggarakan sekolah/training center

- Memanfaatkan hubungan yang harmonis dengan seluruh unit untuk melancarkan kegiatan operasional

4. Analisis kelemahan (W) dan ancaman (T) :

- Memaksimalkan potensi karyawan yang ada dengan melakukan training dan pemberian insentif

- Melakukan kodifikasi pengetahuan untuk meminimalisir pengetahuan yang keluar

Setelah mengolah hasil kuesioner strategi bisnis dengan uji beda independen/bebas hasilnya adalah sebagai berikut :

Group Statistics

Tabel 3 Hasil uji beda strategi bisnis

\begin{tabular}{|ll|l|l|l|ll|}
\hline \multicolumn{1}{|c|}{$\begin{array}{l}\text { Strategi } \\
\text { Bisnis }\end{array}$} & $\mathrm{N}$ & Mean & $\begin{array}{l}\text { Std. } \\
\text { Deviation }\end{array}$ & $\begin{array}{l}\text { Std. Error } \\
\text { Mean }\end{array}$ \\
\hline Total & Kodifikasi & 12 & 24.5833 & 3.20393 & .92489 \\
& personalisasi & 12 & 32.0833 & 4.88892 & 1.41131 \\
\hline
\end{tabular}

Sumber : Data primer yang diolah, 2010

Hasil analisis di atas menunjukkan bahwa fokus pengembangan KMS di bagian Diklat adalah personalisasi yaitu lebih fokus pada pertukaran pengetahuan tacit antarkaryawan.

Berdasarkan hasil kuesioner, knowledge gap yang ada di bagian Diklat adalah , pengetahuan yang perlu ditindaklanjuti karena memiliki knowledge gap tinggi, yaitu >1 adalah :

- Career analysis method

- Bahasa inggris

- Cara pembuatan satuan pelajaran

- Analisis sistem

- Administrasi umum

\section{Langkah 3 : Merancang Infrastruktur KM}

Untuk mendukung penerapan Knowledge Management di bagian Diklat perlu dilakukan bebrapa pengembangan diantaranya :

* Topologi yang digunakan diubah dari peer to peer menjadi client and server

* Penyediaan satu buah komputer server dengan spesifikasi :

Intel® Core ${ }^{\mathrm{TM}} 2$ Duo Processor E7500 (3M Cache, $2.93 \mathrm{GHz}, 1066 \mathrm{MHz}$ FSB), HDD 2x 72GB, Gigabyte G31M-ES2C, dan Kingston 2GB PC6400 DDR2 (Spesifikasi komputer server harus lebih tinggi dari spesifikasi komputer client) 
* Penambahan RAM dan HD pada komputer client menjadi

* Kingston 1GB PC6400 DDR2 dan HDD 2x 80GB

* Software Linux/Windows Server 2003/2008

* Software XAMPP dan MOODLE

Langkah 4 : Memeriksa dan Menganalisis Pengetahuan

Berdasarkan hasil wawancara diketahui bahwan kondisi dokumen dan pengetahuan di bagian Diklat adalah sebagai berikut :

- Pengetahuan karyawan sebagian besar berupa tacit knowledge

- Hardcopy dokumen-dokumen yang ada sulit ditemukan dan disimpan karena tidak terklasifikasi sehingga terkadang kerja para karyawan tidak efisien

- Dokumen masih belum dikelola dengan baik sehingga sering terjadi duplikasi hasil pekerjaan

- Bagian Diklat memiliki "bank data" tetapi data yang ada tidak update (banyak datadata dan knowledge yang terdokumentasi pada masing-masing individu)

- Belum ada mekanisme untuk saling berbagi informasi dan knowledge

- Tidak adanya sistem penghargaan/reward

Langkah 5 : Mendesian tim KM

Dalam penelitian kali ini, karena objek penelitiannya adalah bagian dari perusahaan maka yang dirancang bukanlah tim/divisi Knowledge Management tetapi dalam penerapannya di Diklat hanya membutuhkan seorang administrator yang fungsinya sebagai berikut :

- Melakukan perancangan sistem dokumentasi dan implementasinya

- Menjamin beroperasinya portal intranet

- Mengatur hak akses setiap individu dalam portal

- Mengelola administrasi sistem

- Mengelola konten yang akan diupload ke portal

- Melakukan evaluasi rutin atas implementasi Knowledge Management

- Menjalankan program knowledge sharing melalui forum tatap muka yang bervariasi

- Menyediakan fasilitator untuk setiap forum

Langkah 6 : Membuat cetak biru KM

Penerapan model SECI bagian diklat adalah : 
Gambar 2 Penerapan model SECI di Diklat

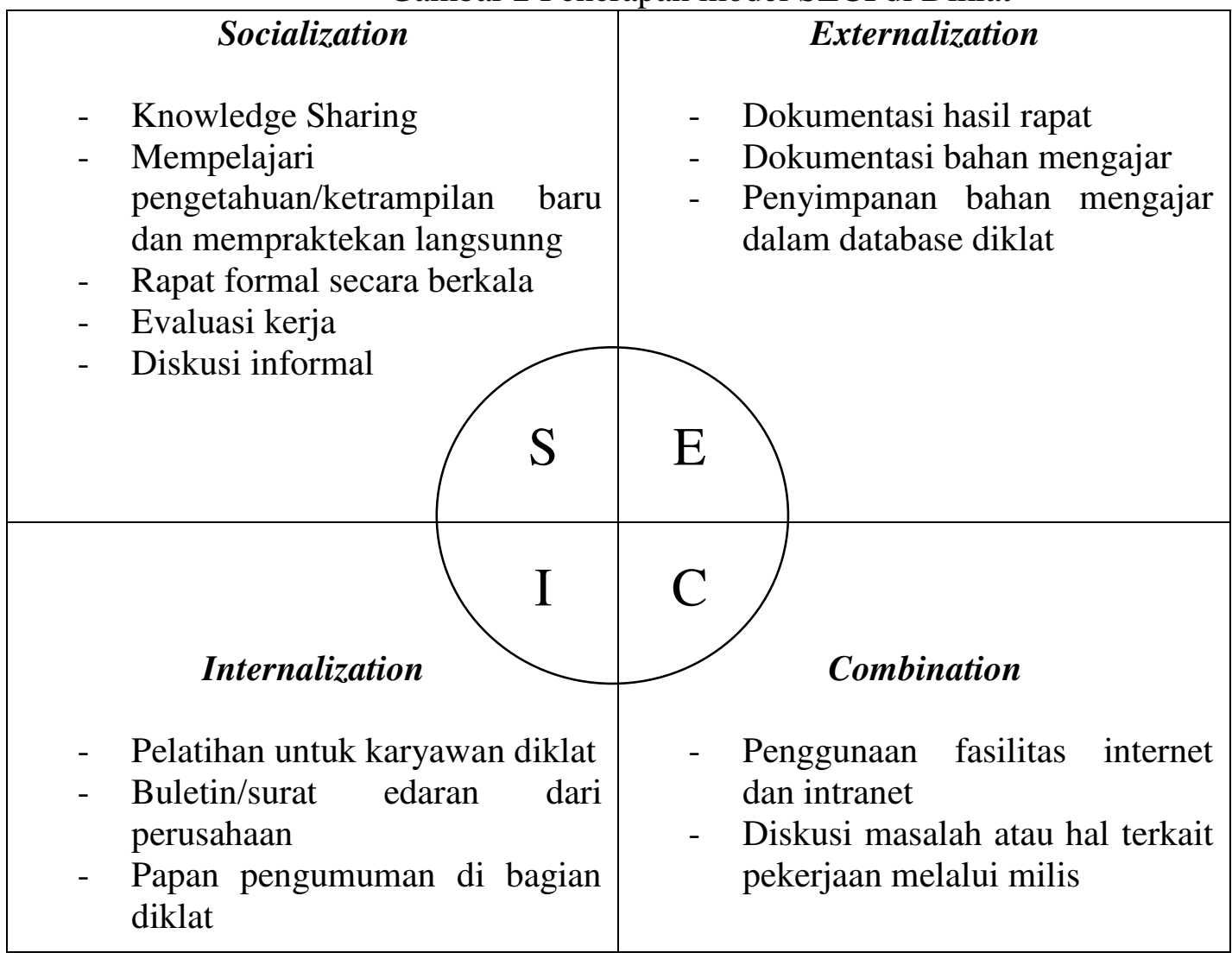

Sumber : data primer yang diolah, 2010

Langkah 7 : Mengembangkan sistem KM

Untuk menerapkan KMS maka perlu dibuat forum online berupa portal intranet dan forum offline berupa forum knowledge sharing secara formal dan berkala. Bentuk forum offline dapat berupa evaluasi pelatihan yang ada dan knowledge sharing materi-materi pelatihan. Portal online yang dibuat menggunakan software MOODLE. 
Gambar 3 user interface portal online

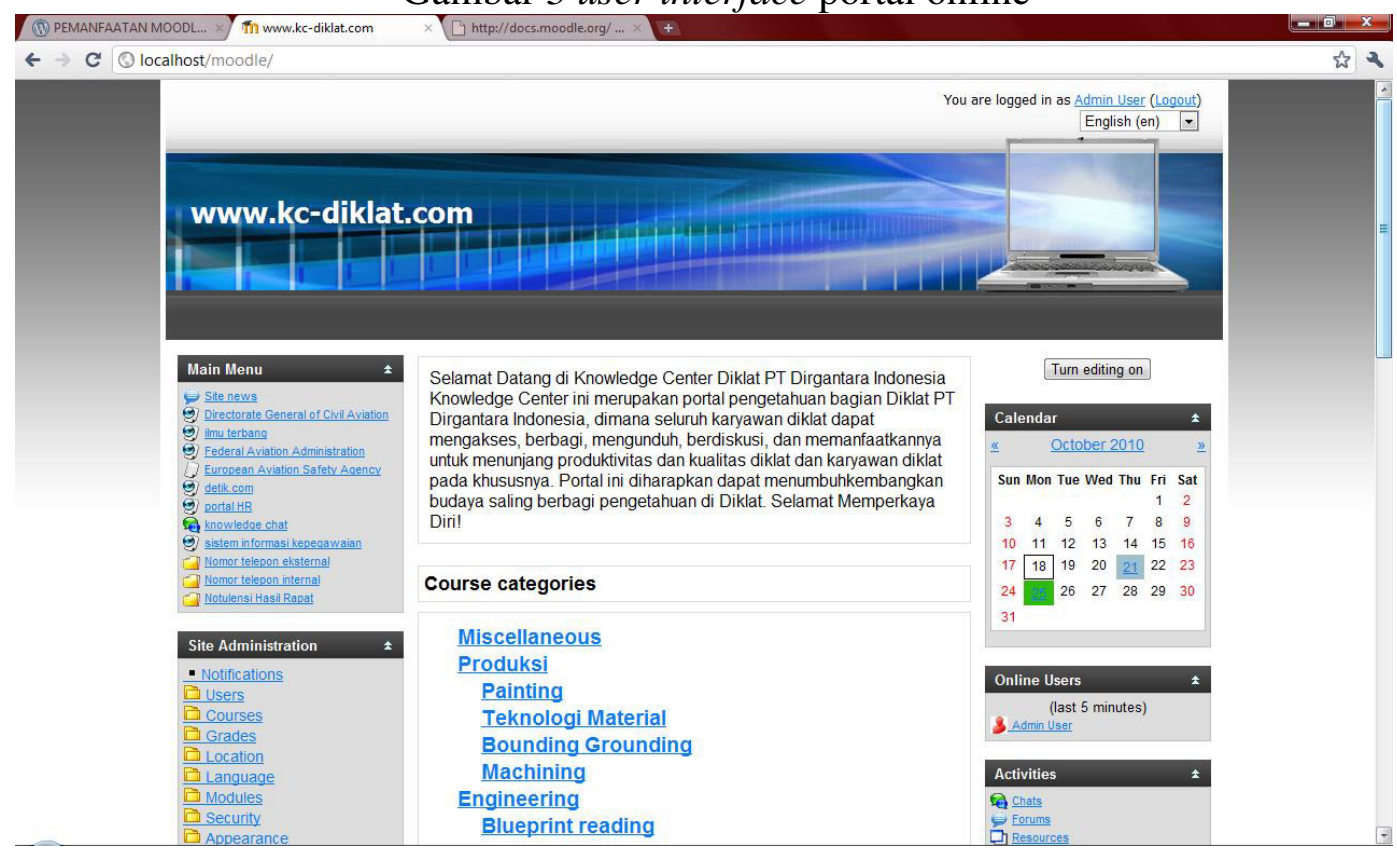

Sumber : Data primer yang diolah, 2010

Langkah 8 : Rencana Implementasi KMS

Dalam implementasinya, seperti yang telah dipaparkan peneliti, tahapan yang harus dilakukan adalah:

1. Mengembangkan infrastruktur yang ada dengan menambahkan komputer server, mengubah topologi yang ada dan menambah software server dan MOODLE

2. Mengangkat seorang administrator yang berasal dari bagian Diklat sendiri yaitu orang yang selama ini bertanggung jawab atas pengelolaan IT.

3. Mengimplementasikan KMS yang berupa portal intranet yang telah dibuat oleh peneliti

4. Menjalankan forum tatap muka secara reguler satu bulan sekali

Forum tatap muka yang dapat dilakukan :

- evaluasi metode mengajar

- evaluasi pelatihan yang ada

- knowledge sharing materi-materi baru yang dapat ditambahkan

- knowledge sharing mengenai buku-buku, ilmu-ilmu baru yang relevan dengan pekerjaan

5. Mengimplementasikan model penerapan SECI yang telah dibuat oleh peneliti

6. Melakukan evaluasi atas penerapan knowledge management yang ada

Langkah 9 : Rencana Pengelolaan Perubahan, Budaya Dan Reward

Tabel 7 Pengelolaan Perubahan

\begin{tabular}{|l|l|}
\hline Kondisi saat ini & Perubahan yang perlu dilakukan \\
\hline Jarang melakukan rapat & Melakukan rapat secara rutin \\
\hline $\begin{array}{l}\text { Belum ada mekanisme } \\
\text { knowledge sharing }\end{array}$ & $\begin{array}{l}\text { Melakukan knowledge sharing baik } \\
\text { secara formal dan informal lewat } \\
\text { forum tatap muka dan forum online }\end{array}$ \\
\hline $\begin{array}{l}\text { Pengetahuan sebagian besar } \\
\text { berupa tacit knowledge }\end{array}$ & Melakukan dokumentasi data \\
\hline
\end{tabular}




\begin{tabular}{|l|l|}
\hline $\begin{array}{l}\text { Hardcopy yang ada sulit } \\
\text { ditemukan }\end{array}$ & Melakukan pengklasifikasian data \\
\hline $\begin{array}{l}\text { Data terdokumentasi pada } \\
\text { masing-masing individu }\end{array}$ & $\begin{array}{l}\text { Menyerahkan data-data untuk } \\
\text { didokumentasikan pada "bank data" }\end{array}$ \\
\hline Tidak adanya sitem reward & Menerapkan KMS berbasis reward \\
\hline $\begin{array}{l}\text { Dokumentasi rapat hanya } \\
\text { pada beberapa individu }\end{array}$ & $\begin{array}{l}\text { Melakukan dokumentasi notulen } \\
\text { rapat pada portal }\end{array}$ \\
\hline $\begin{array}{l}\text { Karyawan sudah tidak } \\
\text { pernah mengupdate "bank } \\
\text { data" }\end{array}$ & $\begin{array}{l}\text { Melakukan update data pada "bank } \\
\text { data" }\end{array}$ \\
\hline $\begin{array}{l}\text { Tidak menggunakan portal } \\
\text { intranet }\end{array}$ & $\begin{array}{l}\text { Membiasakan penggunaan portal } \\
\text { intranet untuk pekerjaan sehari-hari }\end{array}$ \\
\hline
\end{tabular}

Sumber : Data primer yang diolah, 2010

Dalam rangka mendorong terbentuknya budaya knowledge sharing tersebut, bagian Diklat harus memenuhi berbagai persyaratan organisasional atau kultural berikut:

- Adanya komitmen dari manajemen melalui kebijakan, anjuran dan memberi teladan (contoh) knowledge sharing dalam berbagai kesempatan. Keteladanan dapat dilakukan melalui pembuktian bahwa dengan saling berbagi pengetahuan dan pengalaman, semua masalah dapat dipecahkan secara lebih mudah, efisien dan cepat.

- Kepemimpinan dalam KM adalah secara terus menerus dan konsisten memberi inspirasi kepada karyawan tentang aktivitas dan manfaat KM secara nyata bagi semua elemen organisasi. Pemimpin harus menciptakan iklim bahwa seorang karyawan tidak lagi merasa sendirian dalam memecahkan masalah apapun dalam pekerjaan.

- Budaya perusahaan yang memberikan iklim kepercayaan dan keterbukaan

- Adanya kemauan dari pemimpin divisi untuk mempromosikan knowledge sharing dan kolaborasi

- Divisi menghargai knowledge, pembelajaran, dan inovasi

- Memiliki struktur informal yang fleksibel

- Membangun kepercayaan antar karyawan

Dalam penerapannya, di bagian Diklat belum ada penilaian kerja dan tindaklanjutnya seperti reward ataupun insentif.

Rancangan bentuk reward yang dapat diterapkan adalah :

- $\quad$ Forum tatap muka

Setiap kontribusi yang dapat dijadikan perbaikan dan tambahan serta sebagaibahan pengambilan keputusan akan mendapat reward 5\% gaji tetap

- Forum online

Tabel 8 Rancangan reward KMS

\begin{tabular}{|l|l|l|}
\hline $\begin{array}{l}\text { Bentuk } \\
\text { kontribusi }\end{array}$ & Frekuensi & Reward \\
\hline $\begin{array}{l}\text { Akses ke } \\
\text { portal }\end{array}$ & $>30 x /$ bulan & $1 \%$ gaji tetap \\
\hline $\begin{array}{l}\text { Menyimpan, } \\
\text { updating } \\
\text { materi dalam } \\
\text { database }\end{array}$ & $\begin{array}{l}\text { Minimal tiap } \\
\text { adanya } \\
\text { pelatihan }\end{array}$ & $3 \%$ gaji tetap \\
\hline
\end{tabular}




\begin{tabular}{|l|l|l|}
\hline $\begin{array}{l}\text { Knowledge } \\
\text { sharing }\end{array}$ & $>5 \mathrm{x} /$ bulan & $5 \%$ gaji tetap \\
\hline $\begin{array}{l}\text { Interaksi di } \\
\text { forum }\end{array}$ & $>10 \mathrm{x} / \mathrm{bulan}$ & $4 \%$ gaji tetap \\
\hline $\begin{array}{l}\text { Kontribusi } \\
\text { terbaik }\end{array}$ & $\begin{array}{l}\text { Diberikan } \\
\text { training/seminar } \\
\text { sesuai bidangnya }\end{array}$ \\
\hline
\end{tabular}

Sumber : Data primer yang diolah, 2010

Langkah 10 : Membuat instrumen evaluasi KMS

Untuk membuat instrumen evaluasi Knowledge Management System, peneliti mengacu pada pendekatan indikator dari Department of The Navy (DON) Amerika Serikat.

Tabel 9 Indikator performansi KM DON

\begin{tabular}{|c|c|c|c|}
\hline Inisiatif KM & Indikator Sistem & $\begin{array}{l}\text { Indikator } \\
\text { Output }\end{array}$ & Indikator Outcome \\
\hline $\begin{array}{l}\text { Special Interest } \\
\text { Group }\end{array}$ & $\begin{array}{l}\text { - Jumlah Kontribusi } \\
\text { - Frekuensi Update } \\
\text { - Jumlah Anggota } \\
\text { - Rasio jumlah } \\
\text { kontributor dengan } \\
\text { jumlah anggota }\end{array}$ & $\begin{array}{l}\text { - Jumlah } \\
\text { masalah } \\
\text { yang } \\
\text { diselesaikan }\end{array}$ & $\begin{array}{l}\text { - } \text { Peningkatan } \\
\text { mutu dan } \\
\text { efisiensi } \\
\text { - Pengetahuan } \\
\text { yang di } \\
\text { capture }\end{array}$ \\
\hline $\begin{array}{l}\text { Direktori } \\
\text { Expertis }\end{array}$ & $\begin{array}{l}\text { - Jumlah akses ke } \\
\text { situs } \\
\text { - Frekuensi } \\
\text { penggunaan } \\
\text { - Jumlah kontribusi }\end{array}$ & $\begin{array}{l}\text { - waktu } \\
\text { penyelesaian } \\
\text { masalah } \\
\text { - waktu untuk } \\
\text { mencari } \\
\text { expert }\end{array}$ & $\begin{array}{l}\text { - peningkatan } \\
\text { mutu dan } \\
\text { efisiensi } \\
\text { - waktu dan } \\
\text { uang yang } \\
\text { dihemat } \\
\text { melalui } \\
\text { pemanfaatan } \\
\text { knowledge } \\
\text { expert }\end{array}$ \\
\hline $\begin{array}{l}\text { Sistem } \\
\text { Kolaborasi }\end{array}$ & $\begin{array}{l}\text { - Jumlah Pengguna } \\
\text { Jumlah Paten } \\
\text { yang dihasilkan } \\
\text { - Jumlah artikel dan } \\
\text { presentasi yang } \\
\text { dihasilkan }\end{array}$ & $\begin{array}{l}\text { - Jumlah } \\
\text { proyek } \\
\text { - Jumlah } \\
\text { produk baru } \\
\text { - Rata-rata } \\
\text { learning } \\
\text { curve }\end{array}$ & 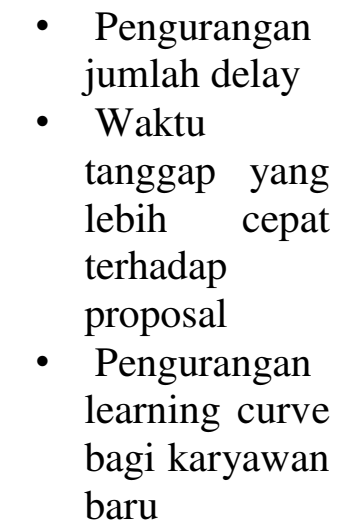 \\
\hline
\end{tabular}

Sumber : metric guide for KM Intitiatives DON, 2005 
Joeliaty

Ajeng Pritha Aryani
Jurnal Manajemen Bisnis Indonesia

Vol.1, Nomor 2, Feb 2014

a. Evaluasi forum online

Tabel 10 Form evaluasi forum online

\begin{tabular}{|l|l|l|l|l|}
\hline No. & Nama Karyawan & $\begin{array}{l}\text { Waktu } \\
\text { akses }\end{array}$ & $\begin{array}{l}\text { Informasi/bentuk } \\
\text { kontribusi }\end{array}$ & $\begin{array}{l}\text { Jumlah } \\
\text { Kontribusi }\end{array}$ \\
\hline & & & & \\
\hline
\end{tabular}

Sumber : Data primer yang diolah, 2010

Selain itu MOODLE dalam fiturnya jg terdapat menu reports yang dapat menunjukkan aktivitas pengguna pada web. Berikut contoh laporannya :

Gambar 4 Fitur report di MOODLE

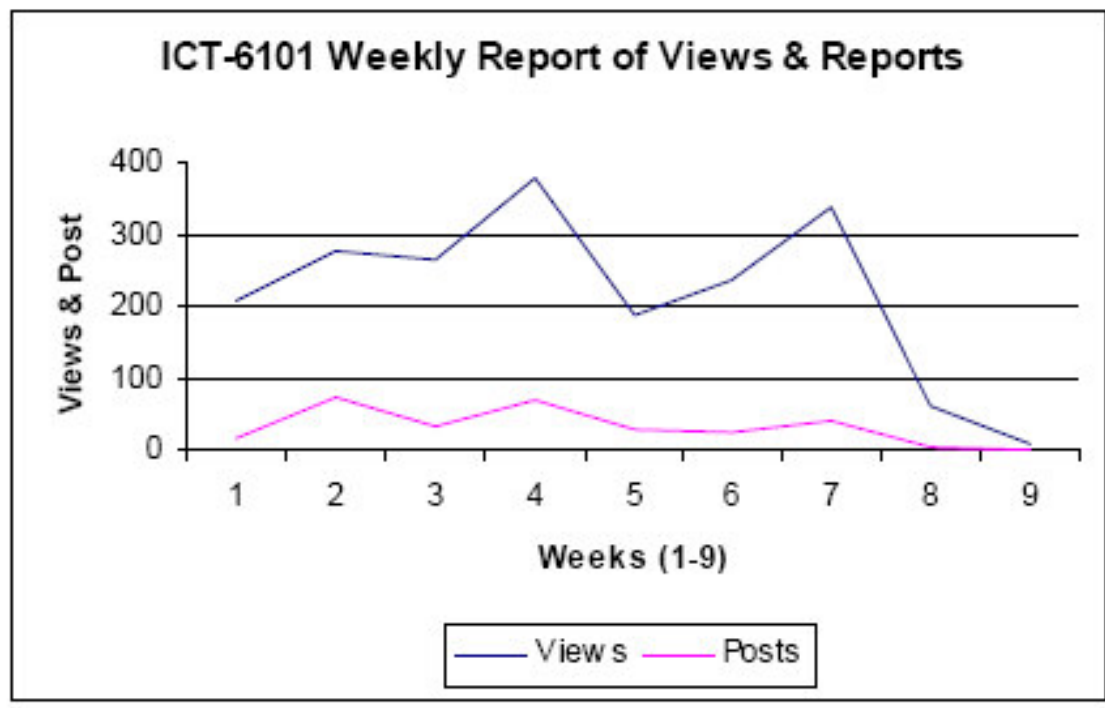

Weekly Report for 2 Courses

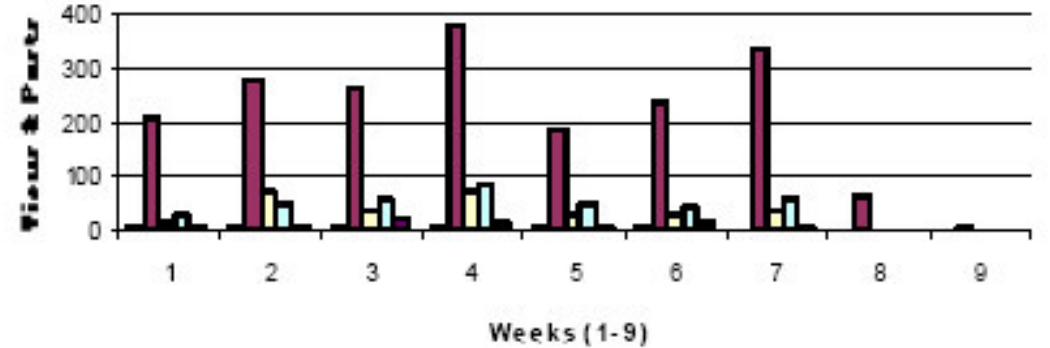

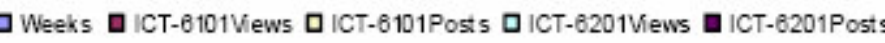




\section{Gambar 5 Live Log MOODLE}

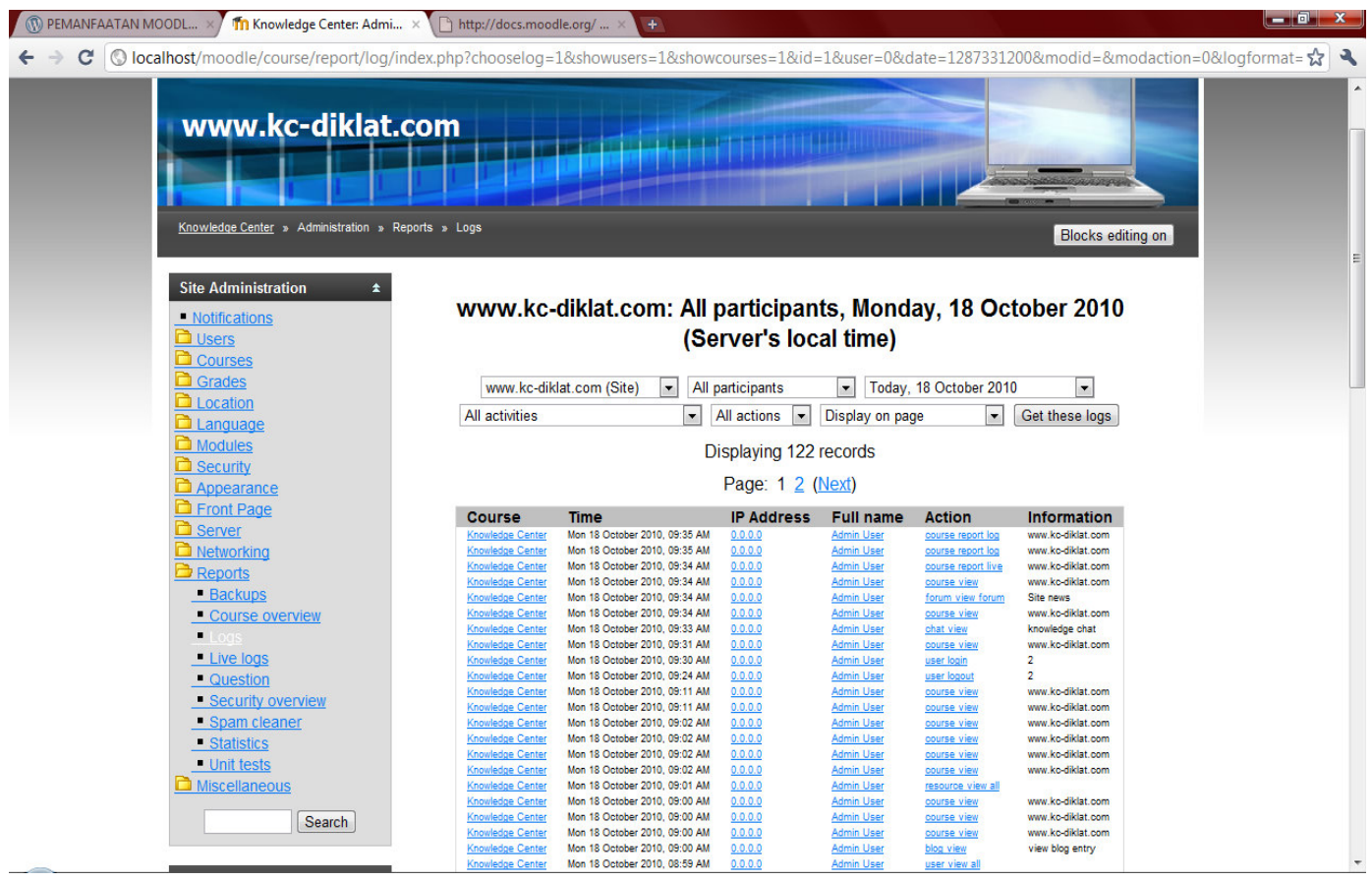

b. Evaluasi forum offline

Tabel 11 Form evaluasi forum offline

\begin{tabular}{|l|l|l|l|l|}
\hline No. & Nama Karyawan & kehadiran & Informasi & $\begin{array}{l}\text { Jumlah } \\
\text { Kontribusi }\end{array}$ \\
\hline & & & & \\
\hline
\end{tabular}

Rencana pengukuran ROI KMS di bagian Diklat :

Tabel 12 Rencana pengukuran ROI KMS

\begin{tabular}{|c|c|c|}
\hline No. & Deskripsi & Jumlah Unit \\
\hline \multicolumn{3}{|c|}{ Cost } \\
\hline 1 & Biaya Pengembangan & \\
\hline a. & $\begin{array}{l}\text { Perangkat Lunak dan Keras yang } \\
\text { Baru } \\
\text { 1. Pengembangan Hardware } \\
\text { Server } \\
\text { 2. Server Operating System } \\
\text { 3. Pengembangan Hardware } \\
\text { Client }\end{array}$ & $\begin{array}{l}1 \text { unit } \\
1 \text { unit } \\
1 \text { paket } \\
12 \text { unit }\end{array}$ \\
\hline b. & Biaya Lain & \\
\hline
\end{tabular}




\begin{tabular}{|l|l|l|}
\hline & $\begin{array}{l}\text { 1. Pelatihan bagi operator dan } \\
\text { manajemen } \\
\text { Maintanance perangkat dan } \\
\text { jaringan }\end{array}$ & \\
\hline Benefit & \\
\hline 1. & Peningkatan produktivitas karyawan & \\
\hline $\mathbf{2 .}$ & Efisiensi biaya training & \\
\hline 3. & Lebih sedikit kesalahan yang terjadi & \\
\hline $\mathbf{4 .}$ & Efisiensi biaya operasional & \\
\hline $\mathbf{5 .}$ & $\begin{array}{l}\text { Efisiensi waktu karyawan menjadi } \\
\text { level produktif setelah pelatihan }\end{array}$ & \\
\hline
\end{tabular}

Benefit yang disebutkan pada tabel di atas bisa terjadi karena dengan penerapan knowledge management system para karyawan diberi fasilitas lengkap untuk mendapatkan ilmu dan pembelajaran sehingga kualitas dan produktivitas pekerjaannya akan meningkat. Dengan demikian biaya training dan operasional akan bisa semakin ditekan. Kemudian, adanya dokumentasi data dengan klasifikasi data yang baik akan menurunkan tingkat kesalahan yang dilakukan karyawan. Selain itu, dengan metode konversi pengetahuan yang tepat akan memperpendek kurva belajar para karyawan sehingga waktu karyawan menjadi level produktif akan menjadi semakin cepat pula.

\section{VI.Kesimpulan Dan Saran}

\subsection{Kesimpulan}

* metodologi knowledge management pada dasarnya terdiri dari menyelaraskan strategi KM dan strategi perusahaan, merancang infrastruktur, merancang tim atau struktur, implementasi yang harus terdapat portal intranet yang mengacu pada seven layers, dan terakhir evaluasi penerapan KM yang menyeluruh.

* Strategi bisnis bagian Diklat adalah strategi personalisasi yaitu lebih fokus pada pertukaran pengetahuan tacit antarkaryawan.

* Pengetahuan yang perlu ditindak lanjuti karena memiliki knowledge gap yang besar adalah career analysis method, bahasa inggris, cara pembuatan SAP, dan analisis sistem.

* Perlu dilakukan pengembangan infrastruktur yaitu pengubahan topologi LAN dari peer to peer menjadi client and srever, penyediaan komputer server, penambahan RAM dan HD pada komputer client, dan penggunaan software windows server, xampp, dan MOODLE

* Kondisi pengetahuan yang ada di bagian Diklat adalah sebagian besar berupa tacit knowledge dan pengelolaan dokumen kurang baik sehingga kerja karyawan kurang efektif dan efisien

* Kebutuhan karyawan tehadap IT tinggi terlihat dari nilai kumulatif jawaban responden mengenai perlunya penambahan beberapa tools IT untuk mendukung pekerjaan sebesar 531 dari 662 yang berarti berada dalam interval kategori setuju.

* Skill karyawan terhadap teknologi tinggi terlihat dari nilai kumulatif jawaban responden mengenai pemahaman menggunakan teknologi sebesar 455 dari 600 yang berarti berada dalam interval kategori setuju.

* Penerapan KMS dilakukan dengan melaksanakan forum online berupa portal intranet dan forum offline berupa forum formal secara berkala 


\subsection{Saran}

- Strategi bisnis Diklat adalah strategi personalisasi maka lebih dibutuhkan berbagai forum tatap muka yang sebagai media knowledge sharing dan knowledge creation.

- Perlu dilakukannya pelatihan untuk menangani pengetahuan yang memiliki knowledge gap yaitu career analysis method, bahasa inggris, cara pembuatan SAP , dan analisis sistem agar gap tersebut dapat hilang

- Melakukan implementasi KMS secara menyeluruh

- Mendeklarasikan peran dan value yang ditawarkan kepada perusahaan. Hal ini penting di samping untuk meyakinkan manajemen dan anggota organisasi lainnya akan perlunya implementasi KM.

- Adanya dukungan atasan dan budaya yang kondusif untuk menciptakan adanya knowledge sharing yang efektif 


\section{V.Daftar Pustaka}

Burk, M. 1999. Knowledge Management : Everyone Benefit by Sharing Information. Public roads Vol 63 No. 3.

Davidson, Carl \& Philip Voss. 2002. Knowledge Management : An Introducing to Creating Competitive Advantage From Intelectual Capital. New Zealand : Tandem Press.

Hansen et al. 1999. What's your strategy for managing knowledge? Harvard Business Review, March-April, pp. 106-115.

Nonaka, Ikoujiro and Hirotaka Takeuchi. 1995. The Knowldedge Creating Company - How Japanese Create The Dynamics of Innovation. New York : Oxford University Press.

Paul L. Tobing. 2007. Knowledge Management : Konsep, Arsitektur, dan Implementasi. Yogyakarta : Graha Ilmu.

Ross, MV dan Schulte, WD. 2005. Knowledge management in a Millitary Enterprise. Elsevier Inc.

Sveiby, K.E. 1998. Measuring Intangible and Intellectual Capital. www.sveiby.com/article/MeasuringIntangibleandIntellectualCapital

Tiwana, Amrit. 2000. The Knowledge Management Toolkit : Practical Techniques for Building A Knowledge Management System. New Jersey : Prentice Hall. 